\title{
Atividade Microbiana em Solo Cultivado com Cana-de-Açúcar após APLICAÇÃo de HeRbicidas ${ }^{1}$
}

\author{
Microbial Activity in Soil Cultivated with Sugarcane after Herbicide Application
}

\author{
REIS, M.R. ${ }^{2}$, SILVA, A.A. ${ }^{3}$, COSTA, M.D. ${ }^{4}$, GUIMARÃES, A.A. ${ }^{5}$, FERREIRA, E.A. ${ }^{2}$, SANTOS, J.B. ${ }^{6}$ e \\ CECON, P.R. ${ }^{7}$
}

\begin{abstract}
RESUMO - Objetivou-se neste trabalho avaliar os efeitos dos herbicidas na atividade respiratória da microbiota, na biomassa microbiana e no quociente metabólico em solo cultivado com plantas de cana-de-açúcar. Utilizou-se o delineamento inteiramente casualizado, no esquema de parcelas subdivididas, com quatro repetições. Nas parcelas, avaliou-se o efeito dos herbicidas e, nas subparcelas, o efeito do tempo após a aplicação destes. Os herbicidas utilizados foram: 2,4-D (1,30 $\left.\mathrm{kg} \mathrm{ha}^{-1}\right)$, ametryn $\left(1,00 \mathrm{~kg} \mathrm{ha}^{-1}\right)$, trifloxysulfuron-sodium $\left(0,0225 \mathrm{~kg} \mathrm{ha}^{-1}\right)$ e a mistura ametryn+trifloxysulfuron-sodium $\left(1,463+0,0375 \mathrm{~kg} \mathrm{ha}^{-1}\right.$, respectivamente). Realizou-se a aspersão dos herbicidas aos 60 dias após a brotação das gemas do material propagativo. Aos 15, 30, 45 e 60 dias após a aplicação dos herbicidas, amostras de solos rizosférico e não-rizosférico foram coletadas e analisadas quanto às seguintes características: taxa respiratória (TR), carbono da biomassa microbiana $(\mathrm{CBM})$, quociente metabólico $\left(\mathrm{qCO}_{2}\right)$ e acúmulo total de $\mathrm{C}-\mathrm{CO}_{2}$ evoluído do solo (ATC). O ametryn aplicado isolado ou em mistura com trifloxysulfuron-sodium propiciou maiores TRs, ao passo que o 2,4-D apresentou pouca influência nessa variável. Maiores acúmulos de $\mathrm{C}-\mathrm{CO}_{2}$ aos 60 dias após a aplicação dos herbicidas foram verificados nos tratamentos com trifloxysulfuron-sodium, ametryn e na mistura de ambos os produtos. A BM do solo foi reduzida na presença do ametryn isolado ou em mistura. Esses tratamentos resultaram em maiores valores de $\mathrm{qCO}_{2}$ aos 45 e 60 dias da aplicação.
\end{abstract}

Palavras-chave: Saccharum spp., biomassa microbiana, quociente metabólico, ametryn, trifloxysulfuronsodium, 2,4-D.

\begin{abstract}
The objective of this work was to evaluate the impact of the herbicides ametryn and trifloxysulfuron-sodium, singly or combined, and 2,4-D, on respiratory rate, microbial biomass, and metabolic quotient on sugar cane-cultivated soil. A completely randomized design was adopted in a split-plot scheme with four replications. The effect of the herbicides was evaluated in the plots and the effect of time after herbicide application in the split-plots. The herbicide doses, in

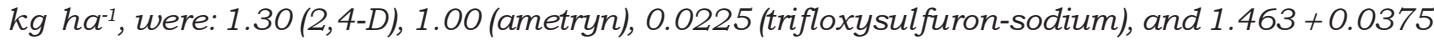
for the mixture ametryn + trifloxysulfuron-sodium, respectively. At 60 days after shoot emergence, the herbicides were sprayed on the sugarcane plants. At 15, 30, 45, and 60 days after herbicide application, rhizospheric and non-rhizospheric soil samples were collected and analyzed for

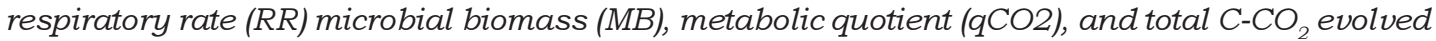
from the soil (TCE). Ametryn applied singly or combined with trifloxysulfuron-sodium led to higher $R R$, while 2, 4-D alone had little influence on this variable. Higher TCEs were verified in the soils of the treatments with trifloxysulfuron-sodium, ametryn, and with the compounds combined. Soil $M B$ was reduced in the presence of ametryn applied singly or combined. These treatments resulted in higher values of $q C O 2$ at 45 and 60 days of application, respectively.
\end{abstract}

Keywords: Sacharum spp., microbial biomass, metabolic quotient, ametryn, trifloxysulfuron-sodium, 2,4-D.

1 Recebido para publicação em 24.4.2007 e na forma revisada em 15.1.2008.

2 Engo-Agrōo, Estudante de Doutorado do Dep. de Fitotecnia, Universidade Federal de Viçosa - UFV, 36570-000, Viçosa-MG, <reisagro@yahoo.com.br>; ${ }^{3}$ D.Sc., Professor Associado do Dep. de Fitotecnia - UFV; ${ }^{4}$ D.Sc., Professor do Dep. de Microbiologia - UFV; ${ }^{5}$ Graduanda em Agronomia - Bolsista de Iniciação Científica/CNPq/UFV; ${ }^{6}$ D. Sc., Professor de Agronomia da FAAG/ Univale, Governador Valadares-MG; ${ }^{7}$ D.Sc., Professor do Dep. de Estatística - UFV. 


\section{INTRODUÇÃO}

No Brasil, o cultivo da cana-de-açúcar destaca-se como uma das mais antigas atividades agroeconômicas, sendo as produções de açúcar e álcool as principais finalidades de sua exploração. Atualmente, é considerada a cultura com maior percentual de crescimento de área cultivada, devido à demanda mundial por combustiveis ambientalmente. Na safra de 2005/ 06, as lavouras canavieiras ocuparam quase seis milhões de hectares, com estimativa de duplicação da área plantada até o ano de 2030 (Magalhães, 2005). No entanto, a expansão de áreas agrícolas, associada a determinados tipos de manejo do solo e fitossanitário (como a aplicação de agrotóxicos), pode comprometer algumas propriedades biológicas do solo (Santos et al., 2005; Tuffi Santos et al., 2005; Vivian et al., 2006).

Algumas técnicas têm-se mostrado eficientes na avaliação dos impactos dos cultivos agrícolas sobre o meio, a exemplo do emprego de indicadores microbiológicos para averiguação da qualidade do solo. Normalmente, pequenas alterações na qualidade do solo estão associadas com mudanças em suas propriedades microbiológicas, as quais apresentam alta sensibilidade a perturbações advindas do manejo (Pankhurst et al., 1997; Tótola et al., 2002).

Dentre os indicadores microbiológicos de qualidade do solo, destacam-se a taxa respiratória (TR), a biomassa microbiana (BM) e o quociente metabólico $\left(\mathrm{qCO}_{2}\right)$. A TR do solo é a medida da produção de $\mathrm{CO}_{2}$ resultante da atividade metabólica dos macro e microrganismos (Doran \& Parkin, 1994). A atividade desses organismos no solo é considerada um atributo positivo para a qualidade do solo e é usada como indicador por ser mais genérica e englobar a atividade de comunidades e consórcios de microrganismos presentes, apresentando melhor reprodutibilidade (Moorman, 1994; Schinner et al., 1996). Altas TRs do solo podem indicar distúrbio ecológico (exemplo, aplicação de agrotóxicos) ou alto nivel de produtividade do ecossistema solo (Islam \& Weil, 1998). A aplicação de agrotóxicos interfere positiva ou negativamente na atividade dos organismos do solo, propiciando a metabolização desses produtos pelos organismos e a capacidade de os agrotóxicos intoxicarem a biota do solo, respectivamente (Santos et al., 2005; Tuffi Santos et al., 2005; Vivian et al., 2006).

A biomassa microbiana do solo é considerada a parte viva da matéria orgânica do solo e inclui bactérias, actinomicetos, fungos, protozoários e algas. Em geral, as estimativas de biomassa são mais abrangentes, pois levam em consideração as populações microbianas cultiváveis e não-cultiváveis (Lin \& Brookes, 1999). Representando a fração viva do solo, a BM está diretamente envolvida na degradação da matéria orgânica, na transformação e disponibilidade dos nutrientes e na degradação de agrotóxicos no solo (Angers et al., 1993; Moormam, 1994). A degradação de agrotóxicos pela BM do solo é amplamente relatada na literatura; no entanto, parte da $\mathrm{BM}$ (organismos não-adaptados) pode ser afetada pelos agrotóxicos. Desse ponto de vista, a BM destaca-se como importante indicador de qualidade do solo.

O quociente metabólico $\left(\mathrm{qCO}_{2}\right)$ consiste na taxa respiratória por unidade de $\mathrm{BM}$ do solo. Maiores valores de $\mathrm{qCO}_{2}$ sugerem condições desfavoráveis aos organismos do solo, e menores valores indicam maior eficiência da BM na utilização dos recursos do ecossistema, ou seja, menos carbono (C) é perdido como $\mathrm{CO}_{2} \mathrm{e}$ maior proporção de $\mathrm{C}$ é incorporada nas células microbianas (Sakamoto \& Obo, 1994). $\mathrm{O} \mathrm{qCO}_{2}$ pode ser considerado o indicador mais adequado para avaliar o efeito das condições de estresse sobre a atividade da BM do solo (Anderson \& Domsch, 1993).

A sensibilidade dos indicadores referidos aos herbicidas foi comprovada em diversos estudos sobre impactos ambientais em solos de clima tropical nas culturas de feijão, cana-deaçúcar e eucalipto (Santos et al., 2005; Tuffi Santos et al., 2005; Vivian et al., 2006).

Do total de herbicidas consumidos no Brasil, aproximadamente $20 \%$ (15 t) são utilizados na cultura da cana-de-açúcar (SINDAG, 2007). Dos herbicidas recomendados para essa cultura, destacam-se o 2,4-D e ametryn como os empregados em maiores quantidades.

O 2,4-D é utilizado no controle de plantas daninhas dicotiledôneas na cultura da canade-açúcar. É classificado como altamente tóxico a humanos e como produto perigoso ao 
ambiente (ANVISA, 2007). Seu efeito sobre a biota do solo manifesta-se com o surgimento e o desaparecimento de algumas espécies de bactérias (Shaw \& Burns, 2004). Para controle de monocotiledôneas na cana-de-açúcar utiliza-se o ametryn, que é classificado como medianamente tóxico a humanos e como produto muito perigoso ao ambiente (ANVISA, 2007). Este herbicida, em mistura com o trifloxysulfuron-sodium, encontra-se disponivel para controle de plantas daninhas mono e dicotiledôneas desde 2001; portanto, há poucas informações sobre o comportamento dessa mistura no ambiente (Syngenta, 2006).

Neste trabalho, objetivou-se avaliar os efeitos dos herbicidas ametryn e trifloxysulfuronsodium, isolados e em mistura, e 2,4-D na atividade microbiana do solo.

\section{MATERIAL E MÉTODOS}

O experimento foi conduzido em casa de vegetação do Departamento de Fitotecnia da Universidade Federal de Viçosa - UFV, e as análises laboratoriais foram realizadas no Laboratório de Herbicida no Solo do Departamento de Fitotecnia/UFV, Viçosa, MG.

O substrato utilizado foi o Latossolo Vermelho-Amarelo, extraído do horizonte B do perfil do solo de área sem histórico de aplicação de agrotóxicos. Para cultivo da cana-de-açúcar, utilizaram-se vasos de PVC de coloração preta, preenchidos com $10 \mathrm{~L}$ de substrato, com o interior revestido por filme de polietileno. O substrato foi corrigido com calcário dolomítico $\left(0,15 \mathrm{~g} \mathrm{dm}^{-3}\right)$ e adubado com sulfato de amônio $\left(0,09 \mathrm{~g} \mathrm{dm}^{-3}\right.$ de $\left.\mathrm{N}\right)$, superfosfato simples $\left(1,8 \mathrm{~g} \mathrm{dm}^{-3}\right.$ de $\left.\mathrm{P}_{2} \mathrm{O}_{5}\right)$ e cloreto de potássio $\left(0,34 \mathrm{~g} \mathrm{dm}^{-3} \mathrm{de} \mathrm{K}_{2} \mathrm{O}\right)$. Posteriormente à correção e adubação, o substrato foi analisado física e quimicamente. A classe textural foi argiloarenosa e apresentou $\mathrm{pH}$ em água de 5,4, CTC (T), CTC (t), H + Al, Ca e Mg de 12,58; 7,30; 5,$28 ; 6,2 ; \mathrm{e} 0,8 \mathrm{cmol}_{\mathrm{c}} \mathrm{dm}^{-3}$, respectivamente; $\mathrm{P}$ e K, respectivamente de 29,5 e $116 \mathrm{mg} \mathrm{dm}^{-3}$; $\mathrm{P}_{\text {rem }}$ de $34 \mathrm{mg} \mathrm{L}^{-1}$; e 4,18 dag $\mathrm{kg}^{-1}$ de matéria orgânica. $\mathrm{O}$ material propagativo de cana-deaçúcar constituiu-se de fragmentos de colmos (tolete contendo uma gema) da variedade RB867515, sendo plantados dois toletes por vaso. Foram também realizadas adubações de cobertura com $100 \mathrm{~mL}$ de solução nutritiva, contendo: adubo Ouro Verde ${ }^{\circledR}$, $\mathrm{N} \mathrm{e}_{2} \mathrm{O}$ nas concentrações de 10,8 e $23,2 \mathrm{~g} \mathrm{~L}^{-1}$, respectivamente, aos 49 e 64 dias após o plantio.

Utilizou-se o delineamento inteiramente casualizado em esquema de parcelas subdivididas; nas parcelas, avaliaram-se os efeitos dos herbicidas e, nas subparcelas, o efeito do tempo após a aplicação desses, com quatro repetições.

Quando as plantas de cana-de-açúcar se encontravam com três a quatro folhas expandidas, as unidades experimentais (vasos com planta+solo) foram aspergidas com solução dos herbicidas 2,4-D, ametryn, trifloxysulfuron-sodium e ametryn+trifloxysulfuron-sodium em concentrações equivalentes às doses de 1,30; 1,00 ; 0,0225 ; e $1,463+0,0375 \mathrm{~kg} \mathrm{ha}^{1}$, respectivamente. $\mathrm{Na}$ aspersão das soluções herbicidas foi utilizado equipamento de aplicação de alta precisão, pressurizado com $\mathrm{CO}_{2}$ e equipado com pontas TT 11002, calibrado previamente para aplicação de $150 \mathrm{~L} \mathrm{ha}^{-1}$ de calda.

Aos 15, 30, 45 e 60 dias após a aplicação das soluções herbicidas (DAA), coletaram-se amostras de solos não-rizosférico e rizosférico. A coleta do solo não-rizosférico foi realizada nas unidades experimentais sem presença de plantas. Para a coleta do solo rizosférico, as plantas foram arrancadas e submetidas à agitação. O solo remanescente no sistema radicular foi coletado para análise. Nessas amostras, estimaram-se a taxa respiratória, o carbono da biomassa microbiana e o quociente metabólico do solo. A umidade atual do solo foi determinada para posterior conversão dos dados obtidos em base solo seco.

Na avaliação da taxa respiratória, utilizouse o método respirométrico de avaliação do C$\mathrm{CO}_{2}$ evoluído do solo, no qual amostras de $100 \mathrm{~g}$ de solo úmido (60\% da capacidade de campo) e peneirado foram incubadas durante 28 dias em frascos hermeticamente fechados. $\mathrm{O} \mathrm{C}-\mathrm{CO}_{2} \mathrm{li}-$ berado do solo foi carreado por fluxo contínuo de ar (isento de $\mathrm{CO}_{2}$ ) até outro frasco contendo $100 \mathrm{~mL}$ de solução de $\mathrm{NaOH}$ 0,25 M. Em intervalos de sete dias, estimou-se o C- $\mathrm{CO}_{2}$ evoluído a partir da titulação de $10 \mathrm{~mL}$ da solução de $\mathrm{NaOH}$ com solução de $\mathrm{HCl}$ 0,1 M, preenchendose novamente os frascos com $100 \mathrm{~mL}$ de solução de $\mathrm{NaOH} 0,25 \mathrm{M}$. No controle da qualidade do ar carreado, utilizou-se frasco sem solo, 
servindo como amostra "em branco" em relação às demais. A temperatura do ar da sala de incubação foi de $25 \pm 2{ }^{\circ} \mathrm{C}$.

Após 28 dias de incubação, o solo foi retirado dos frascos, tomando-se $20 \mathrm{~g}$ de cada frasco para determinação do carbono da biomassa microbiana (CBM). Utilizou-se o método descrito por Vance et al. (1987), modificado por Islam \& Weil (1998), no qual as amostras foram tratadas com radiação de microondas por tempo previamente calculado $(60 s+60 s)$, em vez da fumigação com clorofórmio. O CBM foi extraído das amostras (irradiadas e não-irradiadas) de solo com $80 \mathrm{~mL}$ da solução de $\mathrm{K}_{2} \mathrm{SO}_{4} 0,5 \mathrm{M}$; em seguida, as amostras foram submetidas à agitação por 30 minutos, em mesa agitadora horizontal, permanecendo em repouso durante mais 30 minutos. Após o repouso, as amostras foram filtradas em filtros de papel Whatman no 42 . Em tubo digestor, tomaram-se $10 \mathrm{~mL}$ do filtrado, que foram adicionados aos reagentes: $2 \mathrm{~mL}$ de solução de $\mathrm{K}_{2} \mathrm{Cr}_{2} \mathrm{O}_{7} 0,0667 \mathrm{M}, 5 \mathrm{~mL}$ de $\mathrm{H}_{3} \mathrm{PO}_{4}$ concentrado e $10 \mathrm{~mL}$ de solução de $\mathrm{H}_{2} \mathrm{SO}_{4}$ 0,2 M. Posteriormente, os tubos foram aquecidos por $30 \mathrm{~min}$ a $100{ }^{\circ} \mathrm{C}$, deixando-se esfriar em seguida. $O$ volume foi completado para $100 \mathrm{~mL}$, e adicionado o indicador difenilamina (cinco gotas); em seguida, procedeu-se à titulação com solução $0,033 \mathrm{~mol} \mathrm{~L}^{-1} \mathrm{de}\left(\mathrm{NH}_{4}\right)_{2} \mathrm{Fe}\left(\mathrm{SO}_{4}\right)_{2}$ até mudança da cor azul-escura para verde. A partir dos valores obtidos da evolução do $\mathrm{C}-\mathrm{CO}_{2}$ e CBM, calculou-se o $\mathrm{qCO}_{2}\left(\mu \mathrm{g} \mathrm{g}^{-1} \mathrm{~d}^{-1} \mathrm{de} \mathrm{C}-\mathrm{CO}_{2}\right)$, dividindo-se a média diária do $\mathrm{C}-\mathrm{CO}_{2}$ evoluído do solo pelo CBM determinado no solo. Para estimativa da taxa respiratória do solo, utilizou-se o coeficiente $\beta_{1}$ foi das equações ajustadas e testadas quanto à identidade de modelos. Neste trabalho, o coeficiente $\beta_{1}$, descrito por: $\Delta \beta_{1}=\mathrm{C}-\mathrm{CO}_{2} / \Delta \mathrm{d}$, representando a taxa respiratória do solo, expressa em: $\mu \mathrm{g} \mathrm{g}^{1} \mathrm{~d}^{-1} \mathrm{de} \mathrm{C}$ $\mathrm{CO}_{2}$.

Nas análises estatísticas, optou-se pelo nível de probabilidade de $5 \%$. Os dados foram submetidos à análise de variância, e as médias dos tratamentos qualitativos, comparadas pelo teste de Scott-Knott (1974). Os efeitos dos tempos de incubação e do período após a aplicação dos herbicidas foram avaliados por análise de regressão. A escolha do modelo de regressão foi baseada na significância dos coeficientes do modelo, testados pelo teste t, e no valor do coeficiente de determinação. O modelo de regressão ajustado para o tratamento testemunha (solo rizosférico, sem aplicação de herbicidas) foi comparado com os modelos ajustados para os demais tratamentos, usando-se o teste de identidade de modelos (Regazzi, 1993).

\section{RESULTADOS E DISCUSSÃO}

A evolução de $\mathrm{C}-\mathrm{CO}_{2}$ dos solos em função dos tratamentos apresentou resposta linear $(\mathrm{p}<0,05)$ ao longo do período de incubação (28 dias). As menores taxas respiratórias $\left(\beta_{1}\right)$ foram observadas em amostras do solo nãorizosférico sem aplicação de herbicidas aos 15, 30, 45 e 60 dias após aplicação (DAA) dos tratamentos (Figura 1). Em solos não-rizosféricos encontra-se menor quantidade de microrganismos em relação aos rizosféricos, pelo fato de não haver fornecimento de $\mathrm{C}$ e energia via exsudação radicular das plantas. Portanto, espera-se que a atividade metabólica nos solos não-rizosféricos seja menor (Sandmann \& Loos, 1984).

Solos rizosféricos tratados com trifloxysulfuron-sodium e ametryn+ trifloxysulfuron-sodium e testemunha não diferiram quanto à taxa respiratória do solo aos 15 DAA; portanto, essas taxas respiratórias foram representadas por taxa respiratória comum. Para os solos tratados com ametryn e 2,4-D, as taxas respiratórias foram menores em comparação com a da testemunha (Figura 1). Em solos tratados com os herbicidas aos 30 DAA, as taxas respiratórias não diferiram entre si e foram representadas por uma taxa comum, porém superior à da testemunha (Figura 1). Todos os herbicidas, exceto o 2,4-D, estimularam a respiração dos solos, comparados à testemunha, aos $45 \mathrm{e}$ 60 DAA. As respostas das taxas respiratórias do solo na presença de herbicidas foram variáveis.

Costa et al. (1997) e Moreno (2007) observaram que solos tratados com ametryn, atrazine e glyphosate apresentaram maiores taxas respiratórias em relação ao controle, indicando a possivel metabolização desses herbicidas pela biota do solo. Verificou-se menor acúmulo de $\mathrm{C}-\mathrm{CO}_{2}$ evoluído no solo não-rizosférico (Figura 2), fato explicado pela menor quantidade de organismos presentes. Maiores quantidades de $\mathrm{C}-\mathrm{CO}_{2}$ evoluído foram observadas em solos rizosféricos tratados com ametryn, 

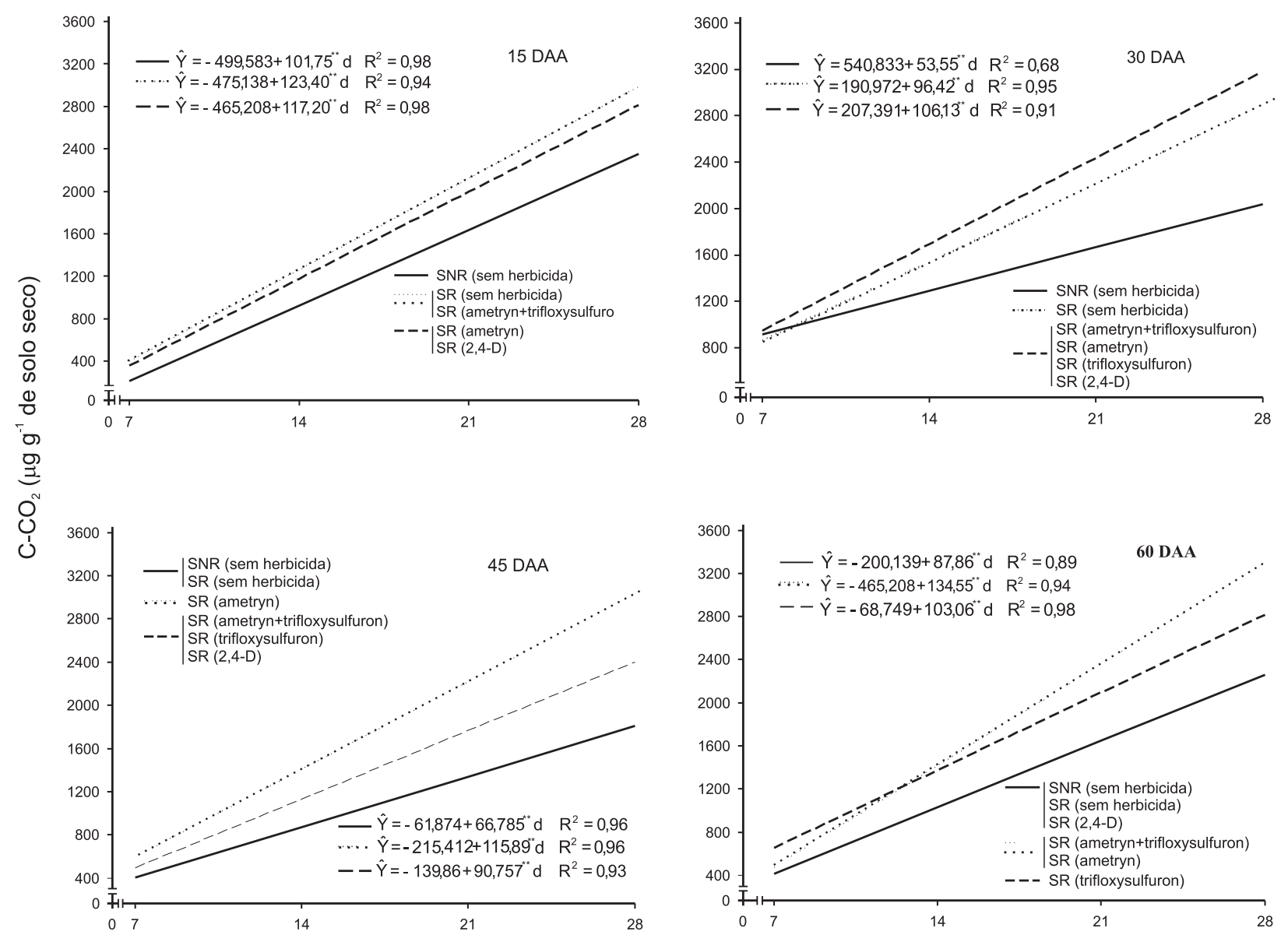

Tempo de incubação (dias)

Figura 1 - Taxas respiratórias $\left(\beta_{1}\right)$, após 28 dias de incubação, das amostras de solo rizosférico (SR) de cana-de-açúcar aos 15, 30, 45 e 60 dias da aplicação dos herbicidas 2,4-D, ametryn, trifloxysulfuron-sodium e ametryn+trifloxysulfuron-sodium e das amostras de solo rizosférico (SR) e solo não-rizosférico (SRN) sem aplicação de herbicidas. Viçosa-MG, 2006.

trifloxysulfuron-sodium e ametryn+trifloxysulfuron-sodium. Esses herbicidas provavelmente provocam desequilíbrio na comunidade microbiana, inibindo determinadas populações microbianas; conseqüentemente, a BM utiliza essas células mortas como fonte de $\mathrm{C}$ e energia no seu metabolismo (Sakamoto \& Obo, 1994). Desse modo, justifica-se, em parte, o aumento da produção de $\mathrm{C}-\mathrm{CO}_{2}$.

Em solos tratados com 2,4-D, não houve diferença no acúmulo de $\mathrm{C}-\mathrm{CO}_{2}$ em relação à testemunha (Figura 2). Sandmann \& Loos (1984) utilizaram o método NMP (Número Mais Provável) para determinar os valores de R:NR (solo rizosférico: solo não-rizosférico) de degradadores do 2,4-D na rizosfera de cana-de-açúcar. Esses autores encontraram valor de R:NR igual a 105 em solos rizosféricos de cana-deaçúcar. Diante disso, sugere-se que a maior concentração de degradadores do 2,4-D na rizosfera da cana-de-açúcar favorece a degradação e incorporação do $\mathrm{C}$ desse produto em células microbianas.

A biomassa microbiana do solo não-rizosférico foi, em média, 45,7\% inferior em relação à do solo rizosférico sem aplicação de herbicida aos 15, 30, 45 e 60 DAA (Tabela 1). O 2,4-D e o trifloxysulfuron-sodium não influenciaram a BM do solo. No entanto, Voos \& Groffman (1997), avaliando os efeitos do 2,4-D no solo, evidenciaram aumento na BM até os 20 DAA, com a estabilização dos 20 aos 80 DAA. Evidenciouse o efeito redutivo na $\mathrm{BM}$, em relação à testemunha, nas amostras de solos tratados com a 


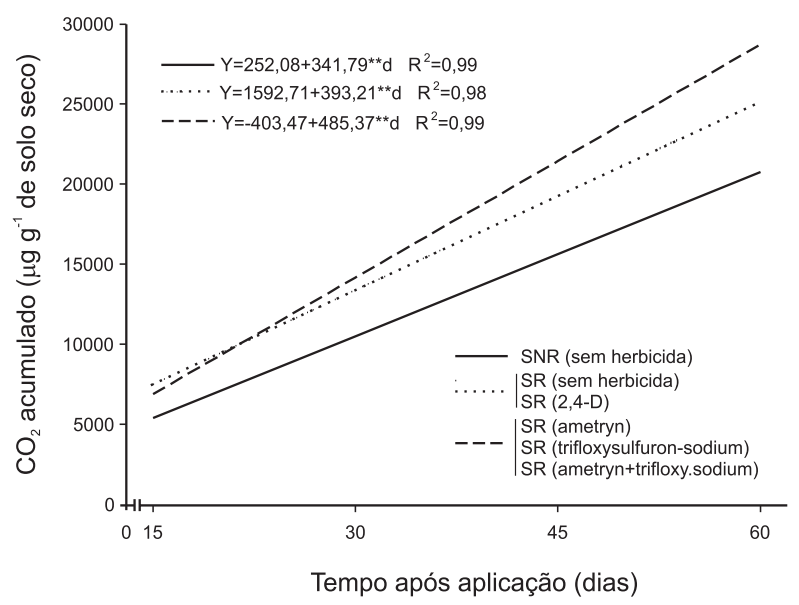

Figura 2 - Acúmulo de C-CO, evoluído nas amostras de solo rizosférico (SR) de cana-de-açúcar após período de 60 dias da aplicação dos herbicidas 2,4-D, ametryn, trifloxysulfuron-sodium e ametryn + trifloxysulfuronsodium e nas amostras de SR e SRN sem aplicação de herbicidas. ${ }^{* *}$ Significativo $(\mathrm{p}<0,01)$. Viçosa-MG, 2006

mistura ametryn+trifloxysulfuron-sodium dos 15 aos 60 DAA (redução média de $23,6 \%$ ) e com ametryn aos 15 DAA (redução média de 14,1\%) (Tabela 1). Esse efeito redutivo devido à aplicação de ametryn, isolado ou em mistura, é surpreendente pelo fato de este ser inibidor do fotossistema II e de a maioria dos microrganismos do solo não ser fotoautotrófica, ou seja, não apresentar capacidade de fixar $\mathrm{CO}_{2}$ atmosférico. Todavia, possiveis efeitos do ametryn sob células microbianas são desconhecidos. Dessa forma, uma provável ação sinérgica dos herbicidas, ou possivelmente a intoxicação dos microrganismos por alguns aditivos da formulação comercial, pode ter contribuído para redução da BM do solo. Santos et al. (2005) avaliaram o efeito dos herbicidas fluazifop- $\rho$-butil e fomesafen, isolados e em mistura, nos atributos biológicos de qualidade do solo cultivado com feijão (Phaseolus vulgaris) em sistema de cultivo convencional e plantio direto. Em ambos os cultivos constataram-se maiores reduções na biomassa microbiana do solo tratado com a mistura de fluazifop- $\rho$-butil e fomesafen.

Os valores de biomassa microbiana do solo encontrados neste trabalho concordam com os obtidos por Santos et al. (2005) em solo cultivado com feijão e por Vivian et al. (2006) em solo cultivado com cana-de-açúcar; ambos
Tabela 1 - Carbono da biomassa microbiana (CBM) e quociente metabólico $\left(\mathrm{qCO}_{2}\right)$ estimados a partir de amostras de solo não-rizosférico sem aplicação de herbicida e de solo rizosférico com aplicação de ametryn + trifloxysulfuronsodium, ametryn, trifloxysulfuron-sodium e 2,4-D, aos 15, 30, 45 e 60 dias após aplicação dos herbicidas (DAA). Viçosa-MG, 2006

\begin{tabular}{|c|c|c|c|c|}
\hline \multirow{2}{*}{ Tratamento } & \multicolumn{4}{|c|}{ DAA } \\
\hline & 15 & 30 & 45 & 60 \\
\hline \multicolumn{5}{|c|}{$\mathrm{CBM}\left(\mu \mathrm{g} \mathrm{CBM} \mathrm{g}^{-1}\right.$ de solo $)-\mathrm{CV}$ parcela $=17,41 \%$} \\
\hline Sem herbicida e planta & $236,73 \mathrm{c}^{1 /}$ & $239,36 \mathrm{c}$ & $237,98 \mathrm{c}$ & $261,57 \mathrm{c}$ \\
\hline Sem herbicida & $449,02 \mathrm{a}$ & $438,14 \mathrm{a}$ & $451,21 \mathrm{a}$ & $460,65 a$ \\
\hline Ametryn & $377,15 \mathrm{~b}$ & $390,33 \mathrm{a}$ & $389,28 \mathrm{a}$ & $388,32 \mathrm{a}$ \\
\hline trifloxysulfuron & $446,86 \mathrm{a}$ & $421,73 \mathrm{a}$ & $442,34 \mathrm{a}$ & $439,60 \mathrm{a}$ \\
\hline Ametryn + trifloxy & $348,90 \mathrm{~b}$ & $335,67 \mathrm{~b}$ & $329,84 \mathrm{~b}$ & $347,50 \mathrm{~b}$ \\
\hline 2,4-D & $415,90 \mathrm{a}$ & $430,45 \mathrm{a}$ & $472,01 \mathrm{a}$ & $469,45 a$ \\
\hline \multicolumn{5}{|c|}{$\mathrm{qCO}_{2}\left(\mu \mathrm{g} \mathrm{C}-\mathrm{CO}_{2} \mu \mathrm{g}^{-1} \mathrm{CBM} \mathrm{d}^{-1}\right)-\mathrm{CV}$ parcela $=29,58 \%$} \\
\hline Sem herbicida e planta & $0,391 \mathrm{a}$ & $0,309 \mathrm{a}$ & $0,318 \mathrm{a}$ & $0,322 \mathrm{a}$ \\
\hline Sem herbicida & $0,253 \mathrm{~b}$ & $0,234 \mathrm{a}$ & $0,156 \mathrm{~b}$ & $0,174 \mathrm{~b}$ \\
\hline Ametryn & $0,271 \mathrm{~b}$ & $0,295 \mathrm{a}$ & $0,255 \mathrm{a}$ & $0,297 \mathrm{a}$ \\
\hline Trifloxysulfuron & $0,229 \mathrm{~b}$ & $0,268 \mathrm{a}$ & $0,185 \mathrm{~b}$ & $0,227 \mathrm{~b}$ \\
\hline Ametryn + trifloxy & $0,305 \mathrm{~b}$ & $0,323 \mathrm{a}$ & $0,248 \mathrm{a}$ & $0,362 \mathrm{a}$ \\
\hline 2,4-D & $0,251 \mathrm{~b}$ & $0,244 \mathrm{a}$ & $0,180 \mathrm{~b}$ & $0,156 \mathrm{~b}$ \\
\hline
\end{tabular}

1/Médias seguidas pela mesma letra na coluna não diferem entre si pelo critério de Scott-Knott $(\mathrm{p}<0,05)$.

os autores estimaram a biomassa microbiana pelo método utilizado neste trabalho. No entanto, estimativas de biomassa microbiana obtidas pelo mesmo método em solo cultivado com cana-de-açúcar foram, em média, o dobro das obtidas neste trabalho. Deve-se ressaltar que esses autores realizaram coletas de amostras de solo em condições de campo em oito diferentes canaviais australianos e utilizaram o método de Amato \& Ladd (1998) para estimativas da BM do solo (Holt \& Mayer, 1998).

A comparação de parâmetros microbiológicos, estimados por diferentes autores, deve ser feita com cautela em razão da não-padronização dos métodos utilizados. Na comparação de métodos para determinação da biomassa microbiana do solo, Andréa \& Hollweg (2004) utilizaram combinações de cinco processos de digestão com oito formas de cálculos do C-microbiano. Esses autores observaram variação de até $1.500 \%$ nos valores de biomassa microbiana obtidos para um mesmo solo arenoso e de quase $900 \%$ em um mesmo solo argiloso. Também, concluíram que o método de Vance et al. (1987), utilizado neste trabalho com 
algumas modificações, é adequado para boa comparação entre os solos e dados da literatura.

A aplicação de herbicidas pode alterar a BM do solo, porém esta apresenta resposta variável e depende do herbicida aplicado, do tipo de solo, da espécie da planta e da microbiota e suas interações. A interação herbicida-solomicrorganismo é demonstrada em alguns trabalhos, onde, por exemplo, o atrazine não provocou alterações na BM de solo arenoso (Ghani et al., 1996) e, por outro lado, favoreceu o aumento da BM em solo argiloso e com alto teor de matéria orgânica (Moreno et al., 2007). Em ambos os trabalhos não houve o cultivo de plantas.

Os herbicidas podem influenciar positiva ou negativamente a microbiota do solo e afetar duas ou mais características biológicas do solo de modo divergente - por exemplo, redução da biomassa microbiana e acréscimo da taxa respiratória - ou de modo convergente - nesse caso, redução ou acréscimo de ambas. Essas condições podem dificultar a interpretação correta dos efeitos de estresse sobre a biota do solo. Assim, para estimativas mais representativas desses efeitos, pode-se obter o $\mathrm{qCO}_{2}$, que relaciona a taxa respiratória com a biomassa microbiana.

Os valores de $\mathrm{qCO}_{2}$ em solos não-rizosféricos foram, de modo geral, 68,6\% maiores nas respectivas avaliações, demonstrando condições de estresse e a limitação de carbono e energia nos solos não-rizosféricos, não proporcionando, desse modo, o pleno crescimento e desenvolvimento dos microrganismos do solo (Sakamoto \& Obo, 1994).

Não se observaram diferenças nos valores de $\mathrm{qCO}_{2}$ das amostras de solos rizosféricos tratadas com herbicidas, em relação à testemunha, aos 15 e 30 DAA. No entanto, aos 45 e 60 DAA, verificou-se aumento do $\mathrm{qCO}_{2}$ em solos rizosféricos tratados com ametryn, isolado e em mistura, respectivamente, sendo isso devido à redução na $\mathrm{BM}$ do solo (Tabela 2).

Não se observou efeito do tempo na biomassa microbiana, Assim, ao analisar o solo rizosférico sem herbicida, constatou-se que a BM foi estável ao longo do tempo. Esse fato a torna um bom indicador de qualidade do solo, ou seja, não houve variação da BM do solo com o desenvolvimento da cultura. Segundo
Tabela 2 - Valores de $\mathrm{qCO}_{2}$ obtidos a partir de amostras de solo não-rizosférico sem aplicação de herbicida e de solo rizosférico com aplicação de ametryn + trifloxysulfuronsodium, ametryn, trifloxysulfuron-sodium e 2,4-D, aos 15, 30, 45 e 60 dias após aplicação dos herbicidas (DAA). Viçosa-MG, 2006

\begin{tabular}{|l|c|c|c|c|}
\hline \multirow{2}{*}{ Tratamento } & \multicolumn{4}{|c|}{$\mathrm{DAA}$} \\
\cline { 2 - 5 } & 15 & 30 & 45 & 60 \\
\hline \multicolumn{4}{|c|}{$\mathrm{qCO}_{2}\left(\mu \mathrm{g} \mathrm{C}-\mathrm{CO}_{2} \mu \mathrm{g}^{-1} \mathrm{CBM} \mathrm{d}{ }^{-1}\right)$} \\
\hline $\begin{array}{l}\text { Sem herbicida e } \\
\text { planta }\end{array}$ & $0,391 \pm 0,07^{/ 1}$ & $0,30 \pm 0,04$ & $0,31 \pm 0,06$ & $0,32 \pm 0,05$ \\
\hline Sem herbicida & $0,253 \pm 0,03$ & $0,23 \pm 0,05$ & $0,15 \pm 0,02$ & $0,17 \pm 0,03$ \\
\hline $\begin{array}{l}\text { Ametryn }+ \\
\text { trifloxy }\end{array}$ & $0,271 \pm 0,01$ & $0,29 \pm 0,01$ & $0,25 \pm 0,03$ & $0,29 \pm 0,04$ \\
\hline Ametryn & $0,229 \pm 0,03$ & $0,26 \pm 0,03$ & $0,18 \pm 0,01$ & $0,22 \pm 0,02$ \\
\hline Trifloxysulfuron & $0,305 \pm 0,04$ & $0,32 \pm 0,05$ & $0,24 \pm 0,03$ & $0,36 \pm 0,03$ \\
\hline 2,4-D & $0,251 \pm 0,07$ & $0,24 \pm 0,01$ & $0,18 \pm 0,01$ & $0,15 \pm 0,02$ \\
\hline
\end{tabular}

${ }_{1 /}^{1 /}$ Médias seguidas pelo erro-padrão da média.

Stenberg (1999), um dos critérios para seleção de indicadores de qualidade do solo é que estes sejam sensiveis a variações em longo prazo no manejo e no clima, mas resistentes a flutuações em curto prazo decorrentes das mudanças climáticas e do desenvolvimento da cultura. Para solos rizosféricos tratados com herbicidas, a não-significância dos coeficientes da equação evidencia que, uma vez afetada a BM do solo pela aplicação desses herbicidas, não houve seu restabelecimento no período de 60 dias da aplicação, demonstrando a não-resiliência desse solo.

No entanto, para o $\mathrm{qCO}_{2}$, os dados não se ajustaram aos modelos polinomiais de primeiro e segundo graus, sendo submetidos à análise estatística descritiva (Tabela 2). Nos tratamentos solo não-rizosférico e solo rizosférico sem herbicida, observou-se decréscimo do $\mathrm{qCO}_{2}$ até os 30 DAA e, posteriormente, sua estabilização. Constatação semelhante foi feita em solos rizosféricos com 2,4-D, provavelmente pelo fato de este herbicida não estar mais afetando TR, em razão da sua degradação no solo. A dissipação do 2,4-D em solos de clima tropical é relativamente rápida, apresentando meia-vida de quatro semanas (Procópio et al., 2003). Para os herbicidas ametryn e trifloxysulfuron-sodium, isolados e em mistura, observou-se que o $\mathrm{qCO}_{2}$ alterou-se de forma distinta da dos outros tratamentos, sendo crescente até os 30 DAA, com redução aos 45 DAA e posterior aumento aos 60 DAA.

Planta Daninha, Viçosa-MG, v. 26, n. 2, p. 323-331, 2008 
Conclui-se que o ametryn, trifloxysulfuronsodium e ametryn + trifloxysulfuron-sodium aumentaram a taxa respiratória e, conseqüentemente, acrescem a quantidade de C$\mathrm{CO}_{2}$ acumulado do solo. O ametryn foi o que mais estimulou a taxa respiratória do solo. Os herbicidas pouco afetaram a biomassa microbiana, com exceção da mistura ametryn+trifloxysulfuron-sodium, reduzindo-a por todo o período de avaliação. O ametryn isolado e em mistura com trifloxysulfuron-sodium propiciou condições estressantes para a microbiota, sendo estas representadas pelos maiores valores de quociente metabólico do solo $\left(\mathrm{QCO}_{2}\right)$. De modo geral, o 2,4-D e o trifloxysulfuron-sodium foram os herbicidas menos prejudiciais à microbiota do solo.

\section{AGRADECIMENTOS}

Ao Conselho Nacional de Desenvolvimento Científico e Tecnológico (CNPq), pelo apoio financeiro para a realização deste trabalho.

\section{LITERATURA CITADA}

AMATO, M.; LADD, J. N. Assay for microbial biomass based on ninhydrin-reactive nitrogen in extracts of fumigated soils. Soil Biol. Biochem., v. 20, n. 1, p. 107-114, 1998

ANDERSON, J. P.; DOMSCH, K. H. The metabolic quotient for $\mathrm{CO}_{2}\left(\mathrm{qCO}_{2}\right)$ as a specific activity parameter to asses the effects of environmental conditions, such as $\mathrm{pH}$, on the microbial biomass of forest soils. Soil Biol.

Biochem., v. 25, n. 3, p. 393-395, 1993.

ANDRÉA, M. M.; HOLLWEG, M. J. M. Comparação de metodos para determinação de biomassa microbiana em dois solos. R. Bras. Ci. Solo, v. 28, n. 6, p. 981-986, 2004.

ANGERS, D. A. et al. Tillage-induced differences in organic matter of particle-size fractions and microbial biomass. Soil Sci Am. J., v. 57, n. 2, p. 512-516, 1993.

AGÊNCIA NACIONAL DE VIGILÂNCIA SANITÁRIA ANVISA. Disponível em: <http://www4 anvisa.gov.br/ agrosia/asp/default.asp>. Acesso em: 1 de março de 2007.

COSTA, M. A.; MONTEIRO, R. T. R.; TORNISIELO, V. L. Influência da adição de palha de cana-de-açúcar na degradação de ${ }^{14} \mathrm{C}$-ametrina em solo areia quartzosa. Sci. Agric., v. 54, n. 3, 1997.

DORAN, J. W.; PARKIN, T. B. Defining and assessing soil quality. In: DORAN, J. M. (Eds.). Defining soil quality for a sustainable environment. Madison: Soil Science Society of America, 1994. p. 3-21. (Special Publication, 35).
GHANI, D. A. et al. Interactions between ${ }^{14} \mathrm{C}$-labelled atrazine and the soil microbial biomass in relation to herbicide degradation. Biol. Fert. Soils, v. 21, n. 1, p. 1722,1996

HOLT, J. A.; MAYER, R. J. Changes in microbial and protease activities of soil associated with long-term sugarcane monoculture. Biol. Fert. Soils, v. 27, n. 1, p. 127131, 1998.

ISLAM, K. R.; WEIL, R. R. Microwave irradiation of soil for routine measurement of microbial biomass carbon. Biol. Fert. Soils, v. 27, n. 4, p. 408-416, 1998.

LIN, Q.; BROOKES, P. C. Comparison of substrate induced respiration, selective inhibition and biovolume of microbial biomass and its community structure in unamended, ryegrass-amended, fumigated and pesticide-treated soils. Soil Biol. Biochem., v. 31, n. 14, p. 1999-2114, 1999.

MAGALHÃES, P. G. 30 anos de Proálcool no centro de debate. Jornal da Unicamp, n. 309, p. 11, 2005

MOORMAN, T. B. Pesticide degradation by soil microrganisms: environmental, ecological and management effects. In: HATFIELD, J. L.; STEWART, B. A. (Eds.). Soil Biology. Effects on soil quality. Boca Raton: CRC Press, 1994. p. 121-169.

MORENO, J. L. et al. Effects of atrazine on microbial activity in semiarid soil. Appl. Soil Ecol., v. 35, n. 1, p. 120127, 2007.

PANKHURST, C. E.; DOUBE, B. M.; GUPTA, V. V. S. R. (Eds.). Biological indicators of soil health. Boca Raton: CRC Press, 1997. 268 p.

PROCÓPIO, S. O. et al. Manejo de plantas daninhas na cultura da cana-de-açúcar. Viçosa, MG: Universidade Federal de Viçosa, 2003. 150 p.

REGAZZI, A. J. Teste para verificar a igualdade de modelos de regressão e a igualdade de alguns parâmetros num modelo polinomial ortogonal. R. Ceres, v. 40, n. 228, p. 176-195, 1993.

SAKAMOTO, K.; OBO, Y. Effects of fungal to bacterial ratio on the relationship between $\mathrm{CO}_{2}$ evolution and total soil microbial biomass. Biol. Fert. Soils, v. 17, n. 1, p. 3944, 1994.

SANDMANN, E. R.; LOOS M. A. Enumeration of 2,4-Ddegrading microorganisms in soils and crop plant rhizospheres using indicator media: high populations associated with sugarcane (Saccharum officinarum). Chemosphere, v. 13, n. 9, p. 1073-1084, 1984. 
SANTOS, J. B. et al. Atividade microbiana do solo após aplicação de herbicidas em sistemas de plantio direto e convencional. Planta Daninha, v. 23, n. 4, p. 683-691, 2005 .

SCHINNER, F. et al. (Eds.). Indirect estimation of microbial biomass. In: SPARLING, G.P. et al. Methods in soil biology. Heidelberg: Springer-Verlag, 1996. p. 47-75.

SHAW, L. J.; BURNS, R. G. Enhanced mineralization of [U14C]2,4-dichlorophenoxyacetic acid in soil from the rhizosphere of Trifolium pretense. Appl. Microbiol. Biotechnol., v. 70, n. 8, p. 4766-4774, 2004.

SINDICATO NACIONAL DA INDÚSTRIA DE PRODUTOS PARA DEFESA AGRÍCOLA - SINDAG

Disponível em: <http://www.sindag.com.br/upload/ compimp0105.xls $>$ Acesso em: 10 de fev. de 2007.

SCOTT, A.; KNOTT, M. Cluster-analysis method for grouping means in analysis of variance. Biometrics, v. 30, n. 3 , p. $507-512,1974$.

STENBERG, B. Monitoring soil quality of arable land: Microbiological indicators. Soil Plant Sci., v. 49, n. 1, p. 124, 1999 .
SYNGENTA FOUNDATION. Disponível em: < http:// www.syngenta. com/en/products_services/ krismat_page.aspx > . Acesso em: 30 de nov. de 2006.

TÓTOLA, M. R.; CHAER, G. M. Microrganismos e processos microbiológicos como indicadores da qualidade dos solos. In: VENEGAS V., H. A. et al. (Eds.). Tópicos em ciência do solo. Viçosa, MG: Sociedade Brasileira de Ciência do Solo, 2002. v. 2. p. 195-276.

TUFFI SANTOS, L. D. et al. Exsudação radicular do glyphosate por Brachiaria decumbens e seus efeitos em plantas de eucalipto e na respiração microbiana do solo. Planta Daninha, v. 23, n. 1, p. 143-152, 2005.

VANCE, E. D.; BROOKES, P. C.; JENKINSON, D. S. An extraction method for measuring soil microbial biomass $\mathrm{C}$. Soil Biol. Biochem., v. 19, n. 6, p. 703-707, 1987.

VIVIAN, R. et al. Persistência de sulfentrazone em Latossolo Vermelho-Amarelo cultivado com cana-de-açúcar. Planta Daninha, v. 24, n. 4, p. 741-750, 2006

VOOS, G.; GROFFMAN, P. Dissipation of 2,4-D and dicamba in a heterogeneous landscape. Appl. Soil Ecol., v. 5, n. 1, p. 181-187, 1997. 